\title{
Antiphospholipid Syndrome Manifested by Gastrointestinal Bleeding: Can We Overlook Endoscopically Revealed Small Lesions?
}

\author{
Satoshi Nakao ${ }^{\text {a }}$ Keiko Akimoto ${ }^{a}$ Masahiko Inamori ${ }^{a}$ Akihiro Suzuki $^{\text {a }}$ Keiko Suzuki $^{\mathrm{a}}$ \\ Hiroshi lida $^{a}$ Hiroki Endo $^{a}$ Tomoyuki Akiyama ${ }^{a}$ Koji Fujita $^{a}$ Masato Yoneda ${ }^{a}$ \\ Hirokazu Takahashi ${ }^{\mathrm{a}}$ Yasunobu Abe ${ }^{\mathrm{a}}$ Noritoshi Kobayashi ${ }^{\mathrm{a}}$ Kensuke Kubota ${ }^{\mathrm{a}}$ \\ Shoji Yamanaka ${ }^{b}$ Atsushi Nakajima ${ }^{a}$

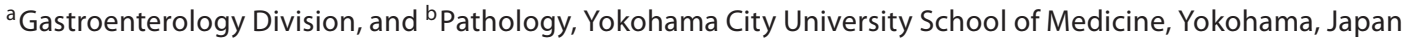

Dear Sir,

A 19-year-old woman was admitted to our hospital with abdominal pain and melena. She had a medical history of habitual abortion. Physical examination of the patient revealed mild reduction of bowel sounds and abdominal pain in the left abdomen. Hematological and biochemical tests were within normal limits. Examinations that included abdominal X-ray, abdominal computed tomography, and radiological enteroclysis failed to reveal the cause of the bleeding. Colonoscopy revealed mucosal redness and edema in the sigmoid colon (fig. 1), and the biopsy findings were compatible with a diagnosis of ischemic colitis. These led to the detection of a highly elevated IgG-anticardiolipin antibody titer of $97(\mathrm{U} / \mathrm{ml})$. We made a diagnosis of antiphospholipid syndrome (APS) with ischemic colitis, and aspirin therapy was started (100 mg/day).

APS is characterized by a clinical syndrome associated with arterial and venous thrombosis, or recurrent fetal losses or thrombocytopenia in the presence of circulating antiphospholipid antibodies, namely lupus anticoagulant and anticar- diolipin antibodies $[1,2]$. In classic APS, thrombus formation is mainly seen in large vessels, and it is common for a single thrombosis to occur at one stage and for another one to occur after an interval [2]. In catastrophic APS, recurring thrombus formation occurs within a short period of time, the condition is characterized by multiple organ failure (e.g. intestinal ischemia, infarctions and involvement of intra-abdominal organs, and symptoms denoting the involvement of the central nervous system), obstruction of two or more vessels, especially small vessels compared with the standard APS, and a high mortality rate [2].

The APS presenting with intestinal involvement has been rarely reported [3]. However, it has become obvious that there is a high frequency of intestinal involvement in catastrophic APS, which is not seen with classic APS [3]. Among classic APS associated with intestinal involvement, the prevalence of clinical manifestations present in patients included gastrointestinal hemorrhage in $14 \%$, and in $4 \%$ the histopathologic finding was ischemic

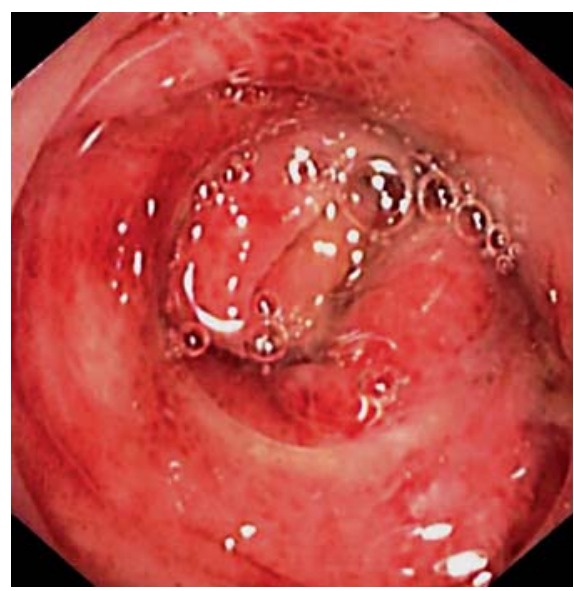

Fig. 1. Colonoscopy findings of mucosal reddening and edema in sigmoid colon.

colitis [3]. Our patient was initially admitted because of melena, secondary to classic APS. We should suspect intestinal involvement secondary to APS even if endoscopy reveals a small lesion.

\section{KARGER}

Fax +41613061234

E-Mail karger@karger.ch

www.karger.com
(C) 2008 S. Karger AG, Basel

0012-2823/08/0774-0139\$24.50/0

Accessible online at:

www.karger.com/dig
Masahiko Inamori, Yokohama City University, School of Medicine

Gastroenterology Division, 3-9, Fukuura, Kanazawa-ku

Yokohama, Kanagawa 236-0004 (Japan)

Tel. +81 457872640 , Fax +81 457843546

E-Mail inamorim@med.yokohama-cu.ac.jp 
References
1 Jürgensen JS, Kettritz R, Schneider W, Koop H, Hildebrand TS, Frei U, Eckardt KU: Catastrophic antiphospholipid syndrome masquerading as ischaemic colitis. Rheumatol Int 2003;23:204-206.

2 Yotsueda $\mathrm{H}$, Tsuruya $\mathrm{K}$, Tokumoto $\mathrm{M}, \mathrm{Hi}$ rakata $\mathrm{H}$, Iida $\mathrm{M}$ : Catastrophic antiphospholipid antibody syndrome following initiation of hemodialysis. Clin Exp Nephrol 2005;9: 335-339.
3 Cervera R, Espinosa G, Cordero A, Oltra MR, Unzurrunzaga A, Rossiñol T, Plaza J, Bucciarelli S, Ramos-Casals M, Ingelmo M, Asherson RA, Font J; Catastrophic Antiphospholipid Syndrome (CAPS) Registry Project Group: Intestinal involvement secondary to the antiphospholipid syndrome (APS): clinical and immunologic characteristics of 97 patients: comparison of classic and catastrophic APS. Semin Arthritis Rheum 2007;36:287-296. 